\title{
ARTICLE
}

Epidemiology and Population Health

\section{Trajectories and determinants of weight gain in two cohorts of young adult women born 16 years apart}

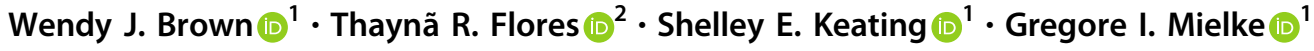

Received: 19 November 2020 / Revised: 7 March 2021 / Accepted: 9 April 2021 / Published online: 3 May 2021

(c) The Author(s), under exclusive licence to Springer Nature Limited 2021

\begin{abstract}
Background The aims were to compare: (1) baseline weights and weight gain trajectories; (2) sociodemographic, behavioural and health characteristics driving weight gain; and (3) estimated average weight in 20 years' time, in two cohorts of young women.

Methods Data were from 16066 participants in two population-based cohorts of young adult women, born in 1973-78 ("GenX") and 1989-95 (“millennials"). Weight was reported at baseline (age 18-23 in both cohorts) and 4 years later. High weight gain was defined as $>2.5 \%$ per year. Data were analysed in 2020 .

Results Women born in 1989-95 were almost $4 \mathrm{~kg}$ heavier at age 18-23 and gained weight over 4 years 1.7 times faster than those born in 1973-78. Prevalence of high weight gain was 34.2\% in the 1989-95 cohort and 24\% in the 1973-78 cohort. In both cohorts, older age, higher education and high physical activity were associated with lower odds of high weight gain, and more hours in paid work, poorer self-rated health and higher baseline BMI were associated with higher odds of high weight gain. Five factors (outer regional areas, one child, ex or current smoker, high stress and depression) were determinants of high weight gain in the 1989-95 cohort, but not in the 1973-78 cohort. Based on average weight at age 21 and annual percentage weight gain, we estimate that women born in 1989-95 will, on average, be $16.7 \mathrm{~kg}$ heavier at age 41 $(93.2 \mathrm{~kg})$, than women in the $1973-78$ cohort $(76.5 \mathrm{~kg})$.

Conclusion High weight gain was evident in every sociodemographic group in both cohorts but most evident in millennial women with high levels of stress and depression. Without effective weight gain prevention strategies we estimate that more than $50 \%$ of the millennial women will be in the obese BMI category in 20 years. This will have serious economic, health and societal consequences.
\end{abstract}

\section{Introduction}

Although the focus of much research on weight gain and the obesity pandemic has focussed on children, and to a lesser extent, on mid-age adults, the 'emerging adulthood'

Supplementary information The online version contains supplementary material available at https://doi.org/10.1038/s41366021-00819-0.

Wendy J. Brown

wbrown@uq.edu.au

1 Centre for Research on Exercise, Physical Activity and Health, School of Human Movement and Nutrition Sciences, The University of Queensland, Brisbane, QLD, Australia

2 Postgraduate Program in Epidemiology, Federal University of Pelotas, Pelotas, Brazil life-stage (18-25 years) is now recognised as a critical period for weight control [1]. This life-stage is associated with transitions in education, work and living situations which may in turn impact on behavioural, psychosocial and environmental factors that are associated with weight gain. Understanding the amounts and trajectories of weight gained in early adulthood, and the determinants of unhealthy weight gain, is critical if we are to develop successful strategies for obesity prevention. This is especially important for women, who because of their reproductive roles, face significant barriers to healthy weight maintenance during their twenties and thirties.

Reports based on analyses of data from serial population surveillance surveys have alerted us to the significant increases in BMI in adult women in the UK and USA since the 1960s [2]. Prospective data on weight gain in young adult women (in their twenties) are however surprisingly rare. Researchers with the US Coronary 
Artery Risk Development in Young Adults (CARDIA) study have reported average annual weight increases over 10 years (among women in their twenties and thirties from $1985 / 86$ to $1995 / 96$ ) of $0.69 \mathrm{~kg} /$ year in White women and $1.19 \mathrm{~kg} /$ year in African-American women. The largest weight gains were among women who were in the overweight and obese BMI categories at baseline [3]. Among female participants in the 1958 British birth cohort study, average weight gain was similar to that of the US white women; on average they gained $0.72 \mathrm{~kg} /$ year between 1981 and 1991, when they were age 23-33 years [4]. As the British researchers noted that most of those in the obese BMI category at age 33 would not have been identified as "fat children", the data support the view that young adulthood is a critical period for weight gain in women. Researchers with the Australian Longitudinal Study on Women's Health (ALSWH) have reported slightly lower rates of weight gain in their 1973-78 cohort, who were age 18-23 at the start of their study in 1996 [5]. On average the women gained 0.61 (95\% CI: $0.580,0.635) \mathrm{kg} / \mathrm{year}$ over 10 years [6]. Average weight gain was somewhat lower again in an analysis of pooled data from seven German cohort studies, which were conducted between 1994 and 2012. Women who were 20-22 at baseline gained between 0.40 and $0.60 \mathrm{~kg} / \mathrm{year}$ in studies with follow-ups of between 4 and 12 years [7].

As women in western high income countries continue to gain weight at these rates, many will transition from the healthy weight range in young adulthood, to becoming overweight or obese in mid-life [8]. The CARDIA researchers have shown that 10 year weight gain in young adults of both races and sexes tends to confer adverse changes in cardiovascular risk factors [9], while, in contrast, weight maintenance in early adulthood is associated with better cardio-metabolic functioning 15 years later, regardless of weight status at baseline [10]. The ALSWH researchers have shown many additional consequences of becoming overweight or obese in young adulthood (e.g. diabetes and asthma [11], depressive symptoms [12], gestational diabetes [13], back pain [14] and urinary incontinence. [15]).

In 2013 the ASLWH researchers recruited a second cohort of women who were the same age at baseline as the 1973-78 cohort (18-23 years), but born 16 years later (in 1989-95) [16]. The first aim of this paper was to compare the baseline weights and weight trajectories of the women in the second cohort with those seen in the first cohort, over the first 4 years of each study (when the women were in their early twenties). The second aim was to compare the associations between baseline sociodemographic, behavioural and health characteristics of each cohort with high rates of weight gain, in order to ascertain whether these were any different for women who were in the same age range during the periods 1996-2000 and 2013-2017. Finally, we used the rates of weight gain in each cohort to predict the average weight of women in each cohort 20 years later.

\section{Methods}

\section{Data sources and participants}

Data were from participants in two birth cohorts of the ALSWH, born in 1973-78 and 1989-95 [5, 16]. Participants in the 1973-78 cohort were randomly selected from a national database (of all Australian permanent residents) in 1995; they completed mailed surveys in 1996 and 2000, then at three yearly intervals to 2018 [17]. Participants in the 1989-95 cohort were selected using a range of methods (including paid Facebook advertising, promotion using social and traditional media, and peer referral); they have completed webbased surveys annually since 2013 [18]. Data from the 1996 and 2000 surveys of the 1973-78 cohort and the 2013 and 2017 surveys of the 1989-95 cohort were used for weight gain analyses, with a 4 year interval between the two surveys in both cohorts.

Recruitment details, baseline characteristics, response and attrition rates have been reported elsewhere [5, 16-18]. At the time of recruitment, women in both cohorts were largely representative of women in the 18-23 year old age group in Australia, but with over-representation of women with University education, especially in the 1989-95 cohort $[5,16]$. Informed consent was obtained from all participants, with ethical clearance from the Universities of Newcastle and Queensland.

As shown in Supplementary Fig. 1, 9688 women in the 1973-78 cohort completed surveys conducted in 1996 (S1) and 2000 (S2), and 8495 women in the 1989-95 cohort completed surveys conducted in 2013 (S1) and 2017 (S2). Of these, women were excluded if they were pregnant at the time of either survey (691 in the first and 303 in the second cohort) or if they did not answer the question about pregnancy. Of the remaining eligible women, 699 (1973-78) and 142 (1989-95) did not answer the questions about weight, leaving 8135 and 7931 women in the analytical samples for each cohort.

\section{Measures}

Copies of the ALSHW surveys, showing the exact wording of each question, can be obtained from the researchers through: https://www.alswh.org.au/for-data-users/data-documentation/ surveys/ 


\section{Weight and weight change}

In each survey, women were asked to report their weight (kg) without clothes or shoes and height (m) without shoes. Weight change was calculated as weight at $\mathrm{S} 2$ minus weight at S1. Average annual percentage weight change, $d$, between $\mathrm{S} 1$ and $\mathrm{S} 2$ was calculated as $d=$ [(W2/ $\left.\mathrm{W} 1)^{1 / 4}-1\right]^{*} 100$, where $\mathrm{W} 1$ and $\mathrm{W} 2$ are weights at successive surveys, 4 years apart. This variable was categorised as: high weight loss, $>2.5 \%$; low weight loss, $2.5 \%$ to $<1.5 \%$; stable weight, $1.5 \%$ to $1.5 \%$; low weight gain, $>1.5 \%$ to $<2.5 \%$; or high weight gain, $\geq 2.5 \%$. BMI was calculated as $\mathrm{kg} / \mathrm{m}^{2}$ and categorised as: underweight $\left(<18.5 \mathrm{~kg} / \mathrm{m}^{2}\right)$; healthy weight $\left(\geq 18.5-<25 \mathrm{~kg} / \mathrm{m}^{2}\right.$; 'overweight' $\left(\geq 25-<30 \mathrm{~kg} / \mathrm{m}^{2}\right)$; or 'obese' $\left(\geq 30 \mathrm{~kg} / \mathrm{m}^{2}\right)$ [19].

\section{Determinants of weight gain}

Selection of potential determinants of weight gain $(\geq 2.5 \%$ per year) was based on variables known from our previous analyses of data from the 1973 to 78 cohort to be associated with weight change, and those identified in previous reviews [20, 21]. To ensure comparability in the analyses, variables were only included if the same questions were asked in the baseline survey of both cohorts. All variables were therefore assessed at S1, with two exceptions: physical activity was assessed at S2, because the questions asked in the baseline surveys of the two cohorts differed; depression was also assessed at S2 because the question was not included at baseline for the 1973-78 cohort.

\section{Socio-demographic characteristics}

Questions were asked at each survey about age, education, area of residence, country of birth, hours of paid work, marital status and number of children, categorised as shown in Table 1.

\section{Health behaviours}

Women were asked to report on smoking (current and former status), alcohol (frequency, and number of standard drinks consumed on each occasion) and responses were categorised as shown in Table 1 [22]. In both second surveys, women were asked about frequency and duration of brisk walking and moderate-intensity and vigorous leisure activities. Responses were used to calculate total physical activity in MET-minutes per week, categorised as shown in Table 1 [23].

\section{Other health-related variables}

Women were asked to report their self-rated health on a five point scale (excellent, very good, good, fair or poor) and
Table 1 Sociodemographic, behavioural and health characteristics of women included in the analysis samples from each cohort, at baseline in 1996 and $2013^{\mathrm{a}}$.

\begin{tabular}{llll}
\hline $1973-78$ & & $1989-95$ \\
& $(N=8135)$ & & $(N=7931)$ \\
& 1996 & & 2013 \\
\cline { 5 - 6 } \cline { 4 - 5 } & $N \quad \%$ & & $N \quad \%$ \\
\hline
\end{tabular}

SOCIODEMOGRAPHIC FACTORS

Age groups (years)

$\begin{array}{lllll}17-18 & 1119 & 13.8 & 1044 & 13.2 \\ 19-20 & 3263 & 40.1 & 2647 & 33.4 \\ 21-22 & 3198 & 39.3 & 2819 & 35.5 \\ 23-24 & 555 & 6.8 & 1421 & 17.9\end{array}$

Education (highest completed)

High school $(<$ Year 11)

$\begin{array}{llll}980 & 12.1 & 360 & 4.7\end{array}$

High school (Year 12)

Trade/Certificate/Diploma

$\begin{array}{llll}4648 & 57.3 & 3634 & 47.2\end{array}$

$\begin{array}{lllll}1397 & 17.3 & 1373 & 17.8\end{array}$

$\begin{array}{llll}1075 & 13.3 & 2334 & 30.3\end{array}$

Tertiary (Bachelor's or higher degree)

Area of residence

Major city

Inner regional

Outer regional

Remote or very remote

Marital Status

Single

In a relationship

Number of children

0

1

$\geq 2$

Hours in paid work (per week)

0

$1-15$

$16-40$

$41+$

BEHAVIOURAL FACTORS

Alcohol Status

Low risk/no-binge

Non-drinker

Low risk/binge

Risky/high risk drinker

4329

$\begin{array}{lll}53.3 & 5902 & 74.4\end{array}$

$\begin{array}{llll}2422 & 29.8 & 1343 & 16.9\end{array}$

$\begin{array}{llll}1141 & 14.0 & 512 & 6.5\end{array}$

$\begin{array}{llll}236 & 2.9 & 172 & 2.2\end{array}$

$\begin{array}{llll}1529 & 18.9 & 1679 & 21.2\end{array}$

$\begin{array}{llll}6570 & 81.1 & 6251 & 78.8\end{array}$

$\begin{array}{llll}7611 & 93.9 & 7638 & 96.3\end{array}$

$\begin{array}{llll}381 & 4.7 & 233 & 2.9\end{array}$

$\begin{array}{llll}117 & 1.4 & 60 & 0.8\end{array}$

$\begin{array}{llll}3781 & 47.0 & 1652 & 20.8\end{array}$

$\begin{array}{llll}962 & 12.0 & 2460 & 31.0\end{array}$

$\begin{array}{llll}2255 & 28.0 & 3326 & 42.0\end{array}$

$\begin{array}{llll}1047 & 13.0 & 489 & 6.2\end{array}$

Smoking Status

Never

Ex-Smoker

Smoker

$\begin{array}{llll}5794 & 72.5 & 6304 & 79.5\end{array}$

$\begin{array}{llll}641 & 8.0 & 565 & 7.1\end{array}$

$\begin{array}{llll}1134 & 14.2 & 825 & 10.4\end{array}$

$\begin{array}{llll}422 & 5.3 & 237 & 3.0\end{array}$

$\begin{array}{llll}4449 & 56.9 & 5425 & 68.4\end{array}$

$\begin{array}{llll}1133 & 14.5 & 1389 & 17.5\end{array}$

$\begin{array}{llll}2231 & 28.6 & 1117 & 14.1\end{array}$

Physical activity (MET-min/week) ${ }^{\mathrm{a}}$ $0-249$

$\begin{array}{llll}1859 & 23.4 & 1262 & 16.1\end{array}$

250-499

$\begin{array}{llll}1269 & 16.0 & 1009 & 12.9\end{array}$

500-749 
Table 1 (continued)

\begin{tabular}{|c|c|c|c|c|}
\hline & \multicolumn{2}{|c|}{$\begin{array}{l}1973-78 \\
(N=8135) \\
1996\end{array}$} & \multicolumn{2}{|c|}{$\begin{array}{l}1989-95 \\
(N=7931) \\
2013\end{array}$} \\
\hline & $N$ & $\%$ & $N$ & $\%$ \\
\hline $750-1000$ & 1017 & 12.8 & 963 & 12.3 \\
\hline $1000-1499$ & 1061 & 13.4 & 1103 & 14.1 \\
\hline $1500+$ & 1860 & 23.4 & 2758 & 35.2 \\
\hline \multicolumn{5}{|l|}{ HEALTH-RELATED FACTORS } \\
\hline \multicolumn{5}{|l|}{ Self-rated health } \\
\hline Excellent & 1061 & 13.1 & 636 & 8.0 \\
\hline Very good & 3267 & 40.4 & 3094 & 39.0 \\
\hline Good & 2867 & 35.4 & 3029 & 38.2 \\
\hline Fair/poor & 896 & 11.1 & 1172 & 14.8 \\
\hline \multicolumn{5}{|l|}{ Body mass index $\left(\mathrm{kg} \cdot \mathrm{m}^{-2}\right)$} \\
\hline Under/normal weight $(<25)$ & 6169 & 77.3 & 5460 & 69.8 \\
\hline Overweight $(25-<30)$ & 1280 & 16.0 & 1441 & 18.4 \\
\hline Obese $(\geq 30)$ & 530 & 6.7 & 922 & 11.8 \\
\hline \multicolumn{5}{|l|}{ Stress score } \\
\hline$<1$ & 4825 & 59.5 & 2908 & 36.7 \\
\hline $1-1.99$ & 2914 & 35.9 & 4048 & 51.0 \\
\hline $2+$ & 373 & 4.6 & 975 & 12.3 \\
\hline \multicolumn{5}{|l|}{ Depression $^{\mathrm{a}}$} \\
\hline No & 7101 & 88.2 & 4713 & 59.5 \\
\hline Yes & 947 & 11.8 & 3214 & 40.5 \\
\hline
\end{tabular}

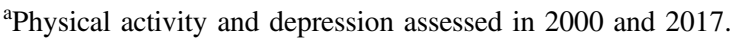

whether they had been "told by a doctor in the last 4 years that they had depression" (1973-78 cohort) or "diagnosed with or treated for depression in the last 12 months" (1989-95 cohort) (yes/no). Perceived stress levels were assessed using an 11-item validated scale with items on specific life domains: own health, health of family members, work/employment, living arrangements, study, money, relationships with family and friends, and motherhood [24]. A mean score (0-4) was derived and categorised as: not stressed $(<1)$; somewhat stressed (1-1.99) or moderately/ very stressed $(\geq 2)$.

\section{Statistical analysis}

Descriptive statistics were used to describe the baseline sociodemographic, behavioural and health-related characteristics of women in each cohort. Proportions of women in each weight gain category were calculated for each cohort, and the proportions in the high weight gain category ( $>2.5 \%$ per annum) were computed for each of the sociodemographic, behavioural and health-related variables. Poisson regression, with robust adjustment for variance, was used to examine associations between these variables
Table 2 Age, weight and weight gain in women in the analysis samples from each cohort.

\begin{tabular}{lll}
\hline & $\begin{array}{l}1973-78 \text { Cohort } \\
N=8135\end{array}$ & $\begin{array}{l}1989-95 \text { cohort } \\
N=7931\end{array}$ \\
\hline Baseline survey year & 1996 & 2013 \\
4 year follow-up year & 2000 & 2017 \\
& Mean (SD) & Mean (SD) \\
Age at baseline (years) & $20.8(1.5)$ & $20.6(1.7)$ \\
Age at follow-up (years) & $24.6(1.5)$ & $24.6(1.7)$ \\
Weight at baseline (kg) & $62.7(12.5)$ & $66.5(15.2)$ \\
$\begin{array}{l}\text { Absolute 4 year weight } \\
\text { change (kg) }\end{array}$ & $2.5(6.9)$ & $4.8(8.5)$ \\
$\begin{array}{l}\text { Annual percentage weight } \\
\text { gain (\% per year) }\end{array}$ & $1.0(2.6)$ & $1.7(2.9)$ \\
\hline
\end{tabular}

and high weight gain, in each cohort. Analyses were adjusted using a hierarchical model in three blocks with the most distal to the most proximal determinants of obesity: (1) sociodemographic; (2) behavioural; and (3) health-related variables. Variables from the first block were retained for the next stage if the $p$ value was $\leq 0.20$. Finally, 20 year weight gain trajectories were calculated using the estimated average annual percentage weight change in the first 4 years. Projected data for the 1973-78 cohort were compared with the actual weights recorded in subsequent surveys, which were administered at 3 yearly intervals from 2000 to 2018. Data were analysed using STATA version 16, in 2020.

\section{Results}

As shown in Supplementary Fig. 1, 8135 and 7931 women were included in the analysis samples from each cohort. The majority $(96.1 \%$ of the $1973-78$ cohort and $96.8 \%$ of the 1989-95 cohort) were born in Australia or another English speaking country. Their baseline (1996 and 2013) sociodemographic, behavioural and health characteristics are shown in Table 1 . The proportions of women with a University degree, living in a major city, and in the paid workforce, were higher in the 1989-95 cohort. The proportions in the highest physical activity, BMI and stress categories, were also greater in this cohort, as was the prevalence of depression. In contrast, the prevalence of smoking was higher in the 1973-78 than in the 1989-95 cohort.

Further details about age, weight and weight gain are shown in Table 2. Although the mean ages at baseline and follow-up were identical in the two cohorts, average baseline weight and average annual percentage weight gain were higher in the 1989-95 cohort (by $3.8 \mathrm{~kg}$ and $70 \%$ respectively) than in the cohort born 16 years earlier.

The proportions of women in each category of average annual percentage weight change (over 4 years) are shown 


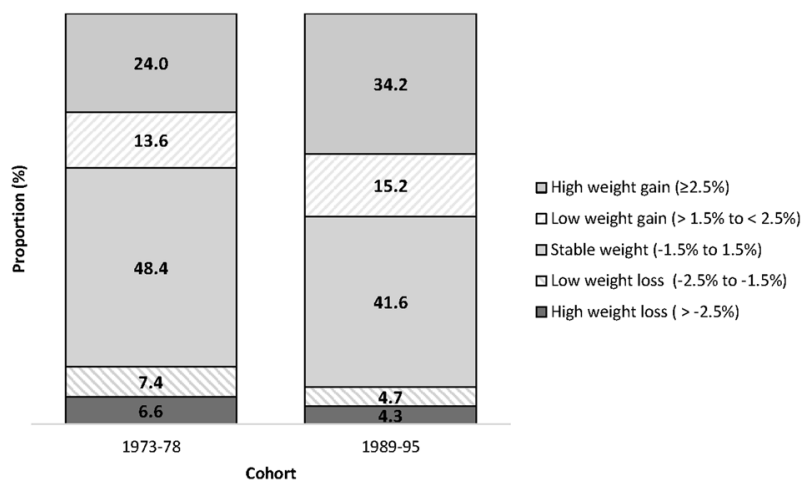

Fig. 1 Average annual percentage weight change over 4 years. Proportions of women in each category of average annual percentage weight change (over 4 years) in the 1973-78 $(N=8135)$ and 1989-95 $(N=7931)$ cohorts

in Fig. 1. More than one-third (34.2\%) of the 1989-95 cohort were categorised as 'high weight gain' $(>2.5 \%$ per year), compared with fewer than one quarter $(24 \%)$ in the 1973-78 cohort. This represents an absolute increase of $10.2 \%$ percentage points and a relative increase in $42.5 \%$ in those categorised as 'high weight gainers' in the 1989-95 cohort, compared with the 1973-78 cohort at the same age.

Cohort differences in the proportion of high weight gainers according to sociodemographic, behavioural and health characteristics are shown in Table 3. In both cohorts, high weight gainers were represented in every category of each of the sociodemographic, behavioural and health variables, but women with University education, high physical activity levels and excellent health were least likely to be high weight gainers. In contrast, in both cohorts, the highest proportions of high weight gainers were among the 17-18 year olds, women with only school education up to year 11, those who worked $>16$ hours/week in paid work, those who reported no physical activity, and those who were in the overweight or obese BMI categories.

As shown in Table 3, there were also cohort differences high weight gainers were over-represented in the 1989-1995 cohort (by at least 50\% relative to the 1973-1978 cohort) among women with year 11 and technical education (trade/ certificate/diploma), those living in outer regional areas, those with one child, ex and current smokers, those with low PA levels, with fair/poor health, high stress scores and depression. The largest relative difference was observed in women with one child, who were $90 \%$ more likely to be in the high weight gain category in the 1989-96 cohort, relative to the 1973-78 cohort. However, there were few mothers in either cohort, and the proportion of women with children was lower in the 1989-95 cohort (3.7\%) than in the 1973-78 cohort (6.1\%; see Table 1).

Crude and adjusted associations between the potential determinants and high weight gain are shown for each cohort in Table 4. Factors associated with lower odds of high weight gain in both cohorts were older age, higher education and high physical activity. In contrast, more hours in paid work, poorer self-rated health and higher BMI were associated with increased odds of high weight gain in both cohorts. Living in an outer regional area, having one child, being an ex or current smoker, and having high stress or depression, were determinants of high weight gain in the 1989-95 cohort but not in the 1973-78 cohort.

Projected 20 year weight gain trajectories, based on the actual weight gain data for the first 4 years, are shown in Fig. 2. In the 1973-78 cohort, based on average weight at age 21 of $62.7 \mathrm{~kg}$, and annual percentage weight gain of $1.0 \%$ per year, we estimate that the average weight at age 41 will be $76.5 \mathrm{~kg}$ (an increase of 22\%). For the 1989-95 cohort, with baseline weight of $66.5 \mathrm{~kg}$ at age 21 , and a $1.7 \%$ annual increase, we estimate that average weight at age 41 will be $93.2 \mathrm{~kg}$ (an increase of 40\%). In Fig. 2, actual average weight data from the eight surveys of the 1973-78 cohort conducted from 1996 to 2018, are superimposed on the projected weight gain trajectory; there was very good agreement between the actual data and predicted estimates.

\section{Discussion}

Data from the ALSWH provided a rare opportunity to compare baseline weights, 4 year weight trajectories, and determinants of high weight gain in two cohorts of women who were in the same 5 year age range, but born 16 years apart. We found that the women who were born later (1989-95) were almost $4 \mathrm{~kg}$ heavier at age 18-23, and gained weight over 4 years at almost twice the rate of the cohort born in the seventies. Based on these data, we estimate that women born in 1989-95 will, on average, be $16.7 \mathrm{~kg}$ heavier at age 41, than women in the 1973-78 cohort. With an average height of $1.66 \mathrm{~m}$ this would mean an average BMI of 33.8. These estimates of weight gain are based on 4 year data from all the women in each cohort, including those who attempted to control their weight by dieting or other means $[25,26]$.

These data ratify previous reports that the 'millennials' (born 1982-99) have higher rates of obesity than 'Gen Xers' (born 1965-81) [2, 27, 28]. However, empirical data on rates of weight gain in millennial women have not been previously reported. Average annual weight gain was much higher in this millennial cohort than in earlier cohorts in Australia (this study), and in the $\mathrm{US}^{3}$ and $\mathrm{UK}^{4}$. If our projections are ratified, the health effects for our millennial cohort will be profound. With average BMI in the obese category, there will be increases in 'mainstream' NCDs such as CVD, diabetes, cancers, osteo-arthritis and mental health problems, and in numerous less frequently cited consequences of obesity such as incontinence, cataracts, 
Table 3 Proportion of women in the high weight gain category ( $>2.5 \%$ per annum) and cohort differences in this proportion according to sociodemographic, behavioural and health characteristics.

\begin{tabular}{|c|c|c|c|c|}
\hline & \multicolumn{2}{|c|}{$\%$ with high weight gain } & \multicolumn{2}{|c|}{ Difference between cohorts } \\
\hline & $\begin{array}{l}1973-78 \% \\
(95 \% \mathrm{CI})\end{array}$ & $\begin{array}{l}1989-95 \% \\
(95 \% \mathrm{CI})\end{array}$ & $\begin{array}{l}\text { Absolute (percentage } \\
\text { points) }\end{array}$ & Relative (\%) \\
\hline Overall & 24.0 & 34.2 & 10.2 & 42.5 \\
\hline \multicolumn{5}{|c|}{ SOCIODEMOGRAPHIC FACTORS } \\
\hline \multicolumn{5}{|c|}{ Age } \\
\hline $17-18$ & $26.9(24.4-29.6)$ & $38.5(35.6-41.5)$ & 11.6 & 43.1 \\
\hline $19-20$ & $23.8(22.4-25.3)$ & $35.8(34.0-37.7)$ & 12.0 & 50.4 \\
\hline $21-22$ & $23.4(21.9-24.9)$ & $32.3(30.6-34.0)$ & 8.9 & 38.0 \\
\hline $23-24$ & $23.1(19.7-26.8)$ & $31.8(29.4-34.3)$ & 8.7 & 37.7 \\
\hline \multicolumn{5}{|c|}{ Education (highest completed) } \\
\hline $\begin{array}{l}\text { High School } \\
(\leq \text { Year 11) }\end{array}$ & $26.0(23.4-28.9)$ & $41.9(36.9-47.1)$ & 15.9 & 61.2 \\
\hline $\begin{array}{l}\text { High School } \\
\text { (Year 12) }\end{array}$ & $24.3(23.0-25.5)$ & $34.7(33.1-36.2)$ & 10.4 & 42.8 \\
\hline $\begin{array}{l}\text { Trade/Certificate/ } \\
\text { Diploma }\end{array}$ & $24.4(22.2-26.7)$ & $40.1(37.6-42.7)$ & 15.7 & 64.3 \\
\hline $\begin{array}{l}\text { Tertiary (Bachelor's } \\
\text { Degree) }\end{array}$ & $20.3(18.0-22.8)$ & $29.5(27.7-31.4)$ & 9.2 & 45.3 \\
\hline \multicolumn{5}{|l|}{ Area of residence } \\
\hline Major city & $23.6(22.3-24.8)$ & $33.4(32.2-34.6)$ & 9.8 & 41.7 \\
\hline Inner regional & $24.6(22.9-26.4)$ & $36.0(33.4-38.6)$ & 11.4 & 46.2 \\
\hline Outer regional & $23.2(20.9-25.8)$ & $38.5(34.4-42.8)$ & 15.3 & 65.7 \\
\hline $\begin{array}{l}\text { Remote or } \\
\text { very remote }\end{array}$ & $29.2(23.8-35.4)$ & $34.9(28.1-42.3)$ & 5.7 & 19.3 \\
\hline \multicolumn{5}{|l|}{ Marital status } \\
\hline Single & $26.9(24.8-29.2)$ & $33.8(31.5-36.1)$ & 6.9 & 25.7 \\
\hline In relationship & $23.3(22.3-24.3)$ & $34.3(33.1-35.5)$ & 11.0 & 47.2 \\
\hline \multicolumn{5}{|l|}{ Number of children } \\
\hline 0 & $24.1(23.2-25.1)$ & $34.0(32.9-35.0)$ & 9.9 & 40.8 \\
\hline 1 & $22.1(18.2-26.5)$ & $42.1(35.9-48.5)$ & 20.0 & 90.1 \\
\hline$\geq 2$ & $23.9(17.1-32.5)$ & $31.7(21.2-44.4)$ & 7.7 & 32.3 \\
\hline \multicolumn{5}{|c|}{ Hours in paid work (per week) } \\
\hline 0 & $22.7(21.4-24.1)$ & $33.2(31.0-35.5)$ & 10.5 & 46.3 \\
\hline $1-15$ & $22.5(19.9-25.2)$ & $31.1(29.3-33.0)$ & 8.6 & 38.5 \\
\hline $16-40$ & $26.0(24.2-27.8)$ & $36.7(35.0-38.3)$ & 10.7 & 41.0 \\
\hline $41+$ & $26.0(23.4-28.7)$ & $35.8(31.7-40.1)$ & 9.8 & 37.8 \\
\hline \multicolumn{5}{|c|}{ BEHAVIOURAL FACTORS } \\
\hline \multicolumn{5}{|c|}{ Alcohol status } \\
\hline Low risk/non-binge & $24.0(22.9-25.1)$ & $34.7(33.5-35.9)$ & 10.7 & 44.7 \\
\hline Non-drinker & $25.7(22.5-29.3)$ & $33.6(29.8-37.6)$ & 7.9 & 30.6 \\
\hline Low risk/binge & $21.4(19.1-23.9)$ & $30.3(27.3-33.5)$ & 8.9 & 41.4 \\
\hline $\begin{array}{l}\text { Risky/high risk } \\
\text { drinker }\end{array}$ & $27.0(23.0-31.5)$ & $35.4(29.6-41.7)$ & 8.4 & 31.2 \\
\hline \multicolumn{5}{|l|}{ Smoking status } \\
\hline Never & $23.4(22.1-24.6)$ & $32.6(31.3-33.8)$ & 9.2 & 39.5 \\
\hline Ex-Smoker & $24.7(22.3-27.3)$ & $37.2(34.6-39.7)$ & 12.4 & 50.3 \\
\hline Smoker & $25.2(23.5-27.1)$ & $38.4(35.6-41.3)$ & 13.2 & 52.2 \\
\hline
\end{tabular}


Table 3 (continued)

\begin{tabular}{|c|c|c|c|}
\hline$\%$ with high & & Difference between $\mathrm{c}$ & \\
\hline $\begin{array}{l}1973-78 \% \\
(95 \% \mathrm{CI})\end{array}$ & $\begin{array}{l}1989-95 \% \\
(95 \% \mathrm{CI})\end{array}$ & $\begin{array}{l}\text { Absolute (percentage } \\
\text { points) }\end{array}$ & Relative (\%) \\
\hline
\end{tabular}

\begin{tabular}{|c|c|c|c|c|}
\hline \multicolumn{5}{|c|}{ Physical activity (MET-min/week) } \\
\hline $0-249$ & $28.5(26.5-30.6)$ & $42.6(39.9-45.4)$ & 14.1 & 49.8 \\
\hline $250-499$ & $23.6(21.3-26.0)$ & $38.5(35.5-41.5)$ & 14.9 & 63.2 \\
\hline $500-749$ & $26.3(23.4-29.3)$ & $36.1(32.7-39.6)$ & 9.8 & 37.3 \\
\hline $750-1000$ & $22.5(20.1-25.2)$ & $35.0(32.0-38.1)$ & 12.5 & 55.4 \\
\hline $1000-1499$ & $24.1(21.6-26.8)$ & $31.3(28.6-34.1)$ & 7.2 & 29.6 \\
\hline $1500+$ & $20.1(18.3-22.0)$ & $29.2(27.5-30.9)$ & 9.1 & 45.0 \\
\hline \multicolumn{5}{|c|}{ HEALTH-RELATED FACTORS } \\
\hline \multicolumn{5}{|c|}{ Self-rated health } \\
\hline Excellent & $18.6(16.3-21.0)$ & $22.3(19.1-25.6)$ & 3.6 & 19.4 \\
\hline Very good & $22.3(20.9-23.8)$ & $30.4(28.8-32.1)$ & 8.1 & 36.3 \\
\hline Good & $27.1(25.5-28.7)$ & $37.6(35.9-39.3)$ & 10.5 & 38.8 \\
\hline Fair/poor & $26.7(23.9-29.7)$ & $42.0(39.2-44.8)$ & 15.3 & 57.4 \\
\hline \multicolumn{5}{|l|}{ Body mass index } \\
\hline Underweight/Normal & $23.0(22.0-24.1)$ & $31.1(29.9-32.4)$ & 8.1 & 35.3 \\
\hline Overweight & $27.7(25.3-30.3)$ & $41.1(38.6-43.6)$ & 13.3 & 48.1 \\
\hline Obese & $27.2(23.6-31.1)$ & $40.1(37.0-43.3)$ & 13.0 & 47.8 \\
\hline \multicolumn{5}{|l|}{ Stress score } \\
\hline$<1$ & $23.1(21.8-24.2)$ & $29.2(27.6-30.9)$ & 6.1 & 26.9 \\
\hline $1-1.99$ & $25.3(23.7-26.9)$ & $35.7(34.2-37.1)$ & 10.4 & 40.9 \\
\hline $2+$ & $27.4(23.1-32.1)$ & $43.1(40.0-46.2)$ & 15.7 & 57.5 \\
\hline \multicolumn{5}{|l|}{ Depression } \\
\hline No & $23.9(22.9-24.9)$ & $30.3(29.0-31.7)$ & 6.5 & 27.0 \\
\hline Yes & $24.3(21.8-27.2)$ & $39.9(38.2-41.6)$ & 15.5 & 63.4 \\
\hline
\end{tabular}

and reproductive health problems [15, 29-32]. This will mean increased health care costs, as previous analyses of ALSWH data have already shown that health care costs are significantly higher for women in the obese BMI category until at least 78 years of age, and that Australian women with obesity have almost twice the number of prescriptions and higher pharmaceutical costs across the lifespan than women with healthy weight [33].

Understanding the factors associated with the differing trajectories of weight gain in these two cohorts is critical to the development of targeted weight gain prevention strategies for the millennial cohort, as most are yet to face the challenges of healthy weight maintenance during their reproductive years. Overall, we expected that the sociodemographic differences between the two cohorts (i.e. lower education, living outside a major city) would underpin a higher overall weight distribution in the 1973-78 than in the 1989-95 cohort, but this was not the case. Although there were some similarities in the sociodemographic, behavioural and health determinants of being in the highest weight gain category ( $>2.5 \%$ per year) in each cohort, there were also important differences. High weight gainers were over-represented among women in the 1989-95 cohort in some sub-groups, most notably women with Year 11 or technical education, those living in outer regional areas, those with one child. High stress levels and depression were more prevalent, but smoking was less prevalent, in the 1989-95 cohort; all three were associated with high weight gain.

High scores on our stress scale may reflect some of the well-known stereotypes of millennial women, in terms of worry about education, part-time work and future career progression and earnings [27]. Time pressures due to work and study may lead to unhealthy eating [34], but as we did not have dietary measures in the first 4 years of the 1989-95 cohort, we could not confirm this was the case here. However, psychosocial stress is a known determinant of weight gain [35] and previous analyses of the ALSWH 1973-78 cohort data have shown that women who reported the most stress gained an additional $2.3 \mathrm{~kg}$ over 9 years, 
Table 4 Crude and adjusted associations (prevalence ratios, PR) between sociodemographic, behavioural and health characteristics with high weight gain in each cohort.

\begin{tabular}{|c|c|c|c|}
\hline \multicolumn{2}{|c|}{$1973-78$ cohort } & \multicolumn{2}{|c|}{ 1989-95 cohort } \\
\hline $\begin{array}{l}\text { Crude PR } \\
(95 \% \text { CI })\end{array}$ & $\begin{array}{l}\text { Adjusted PR } \\
(95 \% \text { CI })\end{array}$ & $\begin{array}{l}\text { Crude PR } \\
(95 \% \text { CI })\end{array}$ & $\begin{array}{l}\text { Adjusted PR } \\
(95 \% \text { CI })\end{array}$ \\
\hline
\end{tabular}

\section{SOCIODEMOGRAPHIC FACTORS}

Age groups

$17-18$

$19-20$

1.00

$21-22$

$0.88(0.79-0.99)$

$0.87(0.77-0.97)$

$0.86(0.72-1.03)$

Education (highest completed)

High School

$(<$ Year 11)

High School

(Year 12)

Trade/Certificate/

Diploma

Tertiary (>Bachelor's

Degree)

Area of residence

Major city
Inner regional
Outer regional
Remote or
very remote
Marital status
Single
In Relationship
Number of children
0
1
$\geq 2$

Hours in paid work (per week)

0

$1-15$

$16-40$

$41+$

\section{BEHAVIOURAL FACTORS}

Alcohol status

$\begin{array}{ll}\text { Low risk/non-binge } & 1.00 \\ \text { Non-drinker } & 1.07(0.93-1.23) \\ \text { Low risk/binge } & 0.89(0.79-1.01) \\ \text { Risky/high risk } & 1.13(0.96-1.33) \\ \text { drinker } & \\ \text { Smoking status } & \\ \text { Never } & 1.00 \\ \text { Ex-Smoker } & 1.06(0.94-1.19) \\ \text { Smoker } & 1.08(0.99-1.18)\end{array}$

1.00

$1.04(0.96-1.14)$

$0.99(0.88-1.11)$

$1.24(1.01-1.52)$

1.00

$0.86(0.79-0.95)$

1.00

1.00

$0.91(0.75-1.11)$

$0.99(0.72-1.37)$

1.00

$1.02(0.93-1.12)$

$0.96(0.85-1.08)$

$1.19(0.96-1.47)$

$0.85(0.77-0.95)$

1.00

0.87 (0.70-1.08)

$0.90(0.64-1.27)$

1.00

$0.99(0.87-1.13)$

1.14 (1.04-1.25)

$1.14(1.02-1.29)$

1.00

$0.99(0.87-1.13)$

$1.17(1.06-1.29)$

$1.16(1.02-1.32)$

1.00

$1.08(0.94-1.25)$

$0.89(0.78-1.01)$

$1.08(0.91-1.29)$

1.00

$1.04(0.92-1.17)$

1.06 (0.96-1.17)

1.00
1.00

$0.93(0.85-1.02)$

$0.84(0.76-0.92)$

$0.83(0.74-0.92)$

1.00

$0.83(0.73-0.94)$

$0.96(0.83-1.10)$

$0.70(0.61-0.81)$

1.00

$1.08(0.99-1.17)$

$1.15(1.03-1.29)$

$1.04(0.85-1.29)$

1.00

$1.02(0.94-1.10)$

1.00

$1.24(1.06-1.44)$

$0.93(0.64-1.35)$

1.00

$0.94(0.86-1.02)$

$1.10(1.02-1.20)$

$1.08(0.94-1.23)$

1.00

0.97 (0.86-1.09)

$0.87(0.78-0.97)$

$1.02(0.86-1.22)$

1.00

1.14 (1.05-1.23)

$1.18(1.08-1.28)$

1.00
1.00

$0.93(0.85-1.03)$

$0.86(0.78-0.95)$

$0.86(0.77-0.98)$

1.00

$0.84(0.73-0.96)$

$0.97(0.84-1.11)$

$0.74(0.64-0.86)$

1.00

1.06 (0.97-1.15)

$1.12(1.00-1.26)$

$1.05(0.86-1.30)$

1.00

$1.02(0.94-1.10)$

1.00

1.31 (1.11-1.53)

$1.02(0.70-1.49)$

1.00

0.97 (0.89-1.07)

$1.19(1.09-1.29)$

$1.20(1.04-1.38)$

1.00

$0.97(0.85-1.09)$

$0.85(0.76-0.94)$

$0.97(0.82-1.16)$

1.00

$1.11(1.03-1.21)$

$1.15(1.05-1.25)$

1.00 
Table 4 (continued)

\begin{tabular}{|c|c|c|c|c|}
\hline & \multicolumn{2}{|l|}{ 1973-78 cohort } & \multicolumn{2}{|l|}{ 1989-95 cohort } \\
\hline & $\begin{array}{l}\text { Crude PR } \\
(95 \% \text { CI })\end{array}$ & $\begin{array}{l}\text { Adjusted PR } \\
(95 \% \mathrm{CI})\end{array}$ & $\begin{array}{l}\text { Crude PR } \\
(95 \% \text { CI) }\end{array}$ & $\begin{array}{l}\text { Adjusted PR } \\
(95 \% \mathrm{CI})\end{array}$ \\
\hline $250-499$ & $0.83(0.73-0.94)$ & $0.82(0.72-0.93)$ & $0.90(0.82-1.00)$ & $0.90(0.81-1.00)$ \\
\hline $500-749$ & $0.92(0.81-1.05)$ & $0.94(0.82-1.08)$ & $0.85(0.75-0.95)$ & $0.86(0.77-0.97)$ \\
\hline $750-1000$ & $0.79(0.69-0.91)$ & $0.78(0.68-0.90)$ & $0.82(0.74-0.91)$ & $0.83(0.75-0.93)$ \\
\hline $1000-1499$ & $0.85(0.75-0.96)$ & $0.83(0.72-0.95)$ & $0.73(0.66-0.82)$ & $0.75(0.67-0.83)$ \\
\hline $1500+$ & $0.71(0.63-0.79)$ & $0.73(0.64-0.82)$ & $0.68(0.63-0.75)$ & $0.69(0.63-0.75)$ \\
\hline \multicolumn{5}{|c|}{ HEALTH-RELATED FACTORS } \\
\hline \multicolumn{5}{|c|}{ Self-rated health } \\
\hline Excellent & 1.00 & 1.00 & 1.00 & 1.00 \\
\hline Very good & $1.20(1.04-1.38)$ & $1.21(1.04-1.40)$ & $1.37(1.17-1.60)$ & $1.28(1.09-1.50)$ \\
\hline Good & $1.46(1.27-1.68)$ & $1.35(1.16-1.57)$ & $1.69(1.45-1.97)$ & $1.42(1.21-1.67)$ \\
\hline Fair/poor & $1.44(1.22-1.70)$ & $1.29(1.07-1.55)$ & $1.89(1.61-2.22)$ & $1.46(1.22-1.73)$ \\
\hline \multicolumn{5}{|l|}{ Body mass index } \\
\hline Underweight/Normal & 1.00 & 1.00 & 1.00 & 1.00 \\
\hline Overweight & $1.20(1.09-1.33)$ & $1.17(1.05-1.30)$ & $1.32(1.23-1.42)$ & $1.21(1.13-1.31)$ \\
\hline Obese & $1.18(1.02-1.37)$ & $1.15(0.99-1.34)$ & $1.29(1.18-1.41)$ & $1.08(0.98-1.19)$ \\
\hline \multicolumn{5}{|l|}{ Stress score } \\
\hline$<1$ & 1.00 & 1.00 & 1.00 & 1.00 \\
\hline $1-1.99$ & $1.10(1.01-1.19)$ & $1.07(0.98-1.17)$ & $1.22(1.14-1.31)$ & $1.10(1.02-1.19)$ \\
\hline $2+$ & $1.19(1.00-1.41)$ & $1.08(0.89-1.31)$ & $1.48(1.35-1.62)$ & $1.25(1.13-1.38)$ \\
\hline \multicolumn{5}{|l|}{ Depression } \\
\hline No & 1.00 & 1.00 & 1.00 & 1.00 \\
\hline Yes & $1.02(0.91-1.15)$ & $0.97(0.86-1.10)$ & $1.31(1.24-1.40)$ & $1.17(1.10-1.25)$ \\
\hline
\end{tabular}

Adjusted analyses used a hierarchical model in three blocks with the most distal to the most proximal determinants of obesity: (1) sociodemographic; (2) behavioural; and (3) health-related variables. Variables from the first block were retained for the next stage if $p$ value $\leq 0.20$

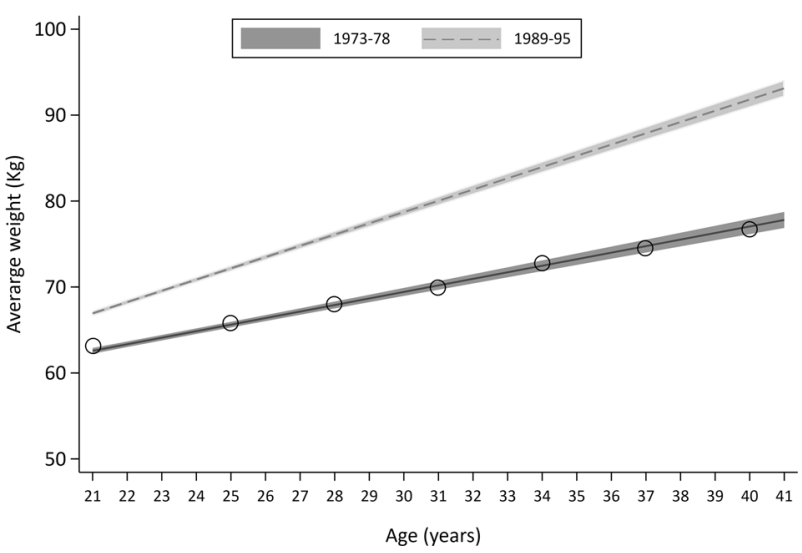

Fig. 2 Trajectories of weight gain. Solid line - 1973-78 cohort, $N=$ 8135; Dashed line - 1989-95 cohort, $N=7931$. Based on data from surveys when average age was 21 and 25 . Round symbols show actual average weight of the women in the 1973-78 cohort at each survey when their average age was $21,25,28,34,37$ and 40 [28].

relative to those who reported less stress [36]. Given that the millennial cohort reported greater levels of stress than the GenX cohort, the complex and likely multi-factorial and bi-directional relationships [37] between stress, smoking, depression and weight gain in our millennial cohort clearly merit further investigation.

The clear inverse dose-response relationship between physical activity and high weight gain in both cohorts, suggests that, despite the marked cohort differences in levels of stress and depression, physical activity may be critical for the prevention of high weight gain. As physical activity can also confer benefits that neutralise the adverse effects of psychosocial stress [38], promotion of higher levels of physical activity physical activity may be particularly pertinent for millennial women. Researchers with the Nurses' and Health Professionals' cohorts have also promoted physical activity as one of the most important contributors to health and well-being with increasing age [29, 39, 40]. Moreover, as obesity has emerged as an important risk factor for hospitalisation during the current COVID-19 pandemic, it is important to note that regular moderate intensity physical activity also reduces morbidity and mortality from viral infection and respiratory illnesses [41]. 
In addition to the 'structured' physical activity assessed in our surveys, it is possible that declines in overall energy expenditure (attributable to decreasing energy expenditure in occupations, at home, and in transport [42]) might explain the higher levels of weight gain in the 1989-95 cohort, and in consecutive generations of women around the world. For example, in the US, daily occupation-related energy expenditure has decreased by more than 100 calories over the last 50 years [43]. Decreases in activity at work, and the higher proportion of millennial women who are in paid work, could therefore account for a proportion of the observed difference in rates of weight gain in these two cohorts. Future research should investigate the role of other determinants, including diet quality and quantity, food availability and preparation styles, as well as potential gut microbiome, genetic and metabolomic factors that may influence energy balance and weight gain [44].

\section{Strengths and limitations}

The strengths of this study are the prospective design and the inclusion of two large nationwide samples of women in the emerging adulthood life-stage, born 16 years apart. Their demographic characteristics are remarkably similar in terms of age, country of birth, marital status and number of children, but there are some important differences. The higher proportion of women living outside major cities in the 1973-78 cohort reflects the intentional over-sampling of rural women in that cohort [17], while cohort differences in other characteristics (such as having a university degree, being in paid work, and smoking) reflect the socio-cultural changes which occurred in Australia in the eighties and nineties Overall, the characteristics of our analysis samples were similar to those of women in the 'parent' cohorts (established in 1996 and 2013), who were, in turn, reasonably representative of Australian women in the same age range [5, 16]. There was however, considerable loss-tofollow up, (see Supplementary Table 1) and overrepresentation of University educated women may have resulted in underestimation of weight and weight gain [45]. Loss-to-follow-up is unlikely to have introduced differential bias, which would affect the magnitude and direction of the associations reported here.

In the ALSWH, we have continuously monitored and improved our survey instruments as new and improved measures have become available. This means that in some cases we have changed the way that variables are assessed. While this may improve the accuracy of measures, it makes longitudinal analysis challenging. A strength of this study was that we only used explanatory variables that were measured using identical (or very similar) questions in both cohorts, so that associations between the potential determinants and high weight gain could be directly compared.
A consequent limitation of the current analyses was that we were unable to include some important determinants of high weight gain (e.g. sitting time, energy intake, dieting and medication use) because the data were not available in both cohorts in this age-matched 4 year period. As in most large cohort studies, another limitation was that all the data were based on self-report, which may mean that our estimates of weight and weight gain may be under-reported, especially by women who are obese [46]. It is therefore possible that under-reporting was slightly greater in the 1989-95 cohort.

\section{Implications}

As more than one quarter of the 1973-78 cohort and onethird of the 1989-95 cohort were 'high weight gainers', and high weight gain ( $>2.5 \%$ per annum) was evident in women in every category of all the measured determinants, weight gain prevention strategies are required for all sub-groups of women. Among the highly stressed millennial cohort, those living in outer regional areas, those with technical education, smokers, and women with young children and with depression warrant specific attention. The data support the view that, without action, women's continued participation in the workforce may be compromised, with increases in illnessrelated absenteeism, and decreased productivity, as well as increased health costs. [27]

\section{Conclusion}

Women in the millennial cohort (1989-95) were significantly heavier and gained weight faster over four years than those in the GenX cohort (1973-78), regardless of sociodemographic and behavioural characteristics. Our projections suggest that, without intervention, millennial women will have an average BMI of 33.8 at age 41. This will have significant health and economic consequences. Weight gain prevention strategies are urgently required, especially as these women negotiate their childrearing years, when rates of weight gain are likely to be even higher.

\section{Data availability}

The data underlying this article were provided by The Australian Longitudinal Study of Women's Health by permission. Information on how to access the data can be found at: https://www.alswh.org.au/how-to-access-the-da ta/alswh-data.

Acknowledgements The research on which this paper is based was conducted as part of the Australian Longitudinal Study on Women's Health by researchers from the University of Queensland and the 
University of Newcastle. We are grateful to the Australian Government Department of Health for funding and to the women who provided the survey data. GIM is supported by a UQ International Development Fellowship; SK is supported by an NHMRC Early Career Research Fellowship (122190). TRF is supported by the Coordination for the Improvement of Higher Education Personnel (CAPES-Brazil).

Author contributions WJB was involved with conception and initiation of the Australian Longitudinal Study on Women's Health, and data collection. WJB, TRF and GIM contributed to the conception and design of this study. GIM and TRF conducted the statistical analyses and all authors contributed to the interpretation of findings. SK and WJB conducted the research for related literature and WJB wrote the initial draft of the paper. All authors contributed to subsequent versions, critically reviewed the paper several times, and approved the final version.

\section{Compliance with ethical standards}

Conflict of interest The authors declare no competing interests.

Publisher's note Springer Nature remains neutral with regard to jurisdictional claims in published maps and institutional affiliations.

\section{References}

1. Lanoye A, Brown KL, LaRose JG. The transition into young adulthood: a critical period for weight control. Curr Diabetes Rep. 2017;17:1-14.

2. Wang YC, McPherson K, Marsh T, Gortmaker SL, Brown M. Health and economic burden of the projected obesity trends in the USA and the UK. Lancet. 2011;378:815-25.

3. Lewis CE, Jacobs DR, McCreath H, Kiefe CI, Schreiner PJ, Smith DE, et al. Weight gain continues in the 1990s: 10-year trends in weight and overweight from the CARDIA study. Am J Epidemiol. 2000;151:1172-81.

4. Power C, Lake JK, Cole TJ. Body mass index and height from childhood to adulthood in the 1958 British birth cohort. Am J Clin Nutr. 1997;66:1094-1101.

5. Dobson AJ, Hockey R, Brown WJ, Byles JE, Loxton DJ, McLaughlin D, et al. Cohort Profile Update: Australian Longitudinal Study on Women's Health. Int J Epidemiol. 2015;44: 1547-1547f.

6. Brown WJ, Hockey R, Dobson AJ. Effects of Having a Baby on Weight Gain. Amer J Prev Med. 2010;38:163-70.

7. Haftenberger M, Mensink GBM, Herzog B, Kluttig A, Greiser $\mathrm{KH}$, Merz B, et al. Changes in body weight and obesity status in German adults: results of seven population-based prospective studies. Eur J Clin Nutr. 2016;70:300-5.

8. Brown WJ, Kabir E, Clark BK, Gomersall SR. Maintaining a Healthy BMI Data From a 16-Year Study of Young Australian Women. Amer J Prev Med. 2016;51:e165-e178.

9. Norman JE, Bild D, Lewis CE, Liu K, West DS. The impact of weight change on cardiovascular disease risk factors in young black and white adults: the CARDIA study. Int $\mathrm{J}$ Obesity. 2003;27:369-76.

10. Truesdale KP, Stevens J, Lewis CE, Schreiner PJ, Loria CM, Cai J. Changes in risk factors for cardiovascular disease by baseline weight status in young adults who maintain or gain weight over 15 years: the CARDIA study. Int J Obesity. 2006;30:1397-1407.

11. Lucke J, Waters B, Hockey R, Spallek M, Gibson R, Byles J, et al. Trends in women's risk factors and chronic conditions: findings from the Australian Longitudinal Study on Women's Health. Women's Health. 2007;3:423-32.

12. Ball K, Burton NW, Brown WJ. A Prospective Study of Overweight, Physical Activity, and Depressive Symptoms in Young Women. Obesity. 2009;17:66-71.

13. Adane AA, Tooth LR, Mishra GD. Pre-pregnancy weight change and incidence of gestational diabetes mellitus: a finding from a prospective cohort study. Diabetes Res Clin Pr. 2017;124:72-80.

14. Brady SRE, Hussain SM, Brown WJ, Heritier S, Billah B, Wang YY, et al. Relationships Between Weight, Physical Activity, and Back Pain in Young Adult Women. Ann Rheum Dis. 2016;75:852.

15. Lamerton TJ, Torquati L, Brown WJ. Overweight and obesity as major, modifiable risk factors for urinary incontinence in young to mid-aged women: a systematic review and meta-analysis. Obes Rev. 2018;19:1735-45.

16. Loxton D, Tooth L, Harris ML, Forder PM, Dobson A, Powers J, et al. Cohort Profile: the Australian Longitudinal Study on Women's Health (ALSWH) 1989-95 cohort. Int J Epidemiol. 2018;47:3 91-392e.

17. Brown WJ, Bryson L, Byles JE, Dobson AJ, Lee C, Mishra G, et al. Women's Health Australia: Recruitment for a national longitudinal cohort study. Women \& Health. 1998;28:23-40.

18. Mishra GD, Hockey R, Powers J, Loxton D, Tooth L, Rowlands I, et al. Recruitment via the Internet and Social Networking Sites: The 1989-95 Cohort of the Australian Longitudinal Study on Women's Health. J Med Internet Res. 2014;16:e279.

19. Davies A, Wellard-Cole L, Rangan A, Allman-Farinelli M. Validity of self-reported weight and height for BMI classification: a cross-sectional study among young adults. Nutrition. 2020;71:110622.

20. Pegington M, French DP, Harvie MN. Why young women gain weight: a narrative review of influencing factors and possible solutions. Obes Rev. 2020;21:e13002.

21. Wane S, van Uffelen JGZ, Brown W. Determinants of Weight Gain in Young Women: a Review of the Literature. J Women's Health. 2010;19:1327-40.

22. Powers JR, Loxton D, Anderson AE, Dobson AJ, Mishra GD, Hockey R, et al. Changes in smoking, drinking, overweight and physical inactivity in young Australian women 1996-2013. Health Promot J Aust. 2017;28:255-9.

23. Brown WJ, Trost SG, Bauman A, Mummery K, Owen N. Testretest reliability of four physical activity measures used in population surveys. J Sci Med Sport. 2004;7:205-15.

24. Bell S, Lee C. Development of the perceived stress questionnaire for young women. Psychol Health Med. 2002;7:189-201.

25. Madigan C, Daley A, Kabir E, Aveyard P, Brown WJ. Cluster analysis of behavioural weight management strategies and associations with weight change in young women: a longitudinal analysis. Int J Obesity. 2015;39:1601-06.

26. Madigan CD, Pavey T, Daley AJ, Jolly K, Brown WJ. Is weight cycling associated with adverse health outcomes? A cohort study. Prev Med. 2018;108:47-52.

27. Deal JJ, Altman DG, Rogelberg SG. Millennials at work: what we know and what we need to do (if anything). J Bus Psychol. 2010;25:191-9.

28. Wang Y, Beydoun MA, Liang L, Caballero B, Kumanyika SK. Will all Americans become overweight or obese? Estimating the progression and cost of the US obesity epidemic. Obesity. 2008; 16:2323-30.

29. Zheng Y, Manson JE, Yuan CZ, Liang MH, Grodstein F, Stampfer MJ, et al. Associations of Weight Gain From Early to Middle Adulthood With Major Health Outcomes Later in Life. J Amer Med Assoc. 2017;318:255-69. 
30. Avila C, Holloway AC, Hahn MK, Morrison KM, Restivo M, Anglin R, et al. An Overview of Links Between Obesity and Mental Health. Curr Obes Rep. 2015;4:303-10.

31. Dağ ZÖ, Dilbaz B. Impact of obesity on infertility in women. J Turk Ger Gynecol Assocn. 2015;16:111-7.

32. Mena GP, Mielke GI, Brown WJ. Do physical activity, sitting time and body mass index affect fertility over a 15 -year period in women? Data from a large population-based cohort study. Hum Reprod. 2020;35:676-83.

33. Mishra G, Chan H, Hockey R, Waller M, Kanesarajah J, Byles J, et al. Future health service use and cost: insights from the Australian Longitudinal Study on Women's Health. In: Report prepared for the Australian Government Department of Health; 2016. (https://espace.library.uq.edu.au/view/UQ:408050).

34. Khaled K, Tsofliou F, Hundley V, Helmreich R, Almilaji O. Perceived stress and diet quality in women of reproductive age: a systematic review and meta-analysis. Nutr J. 2020;19: $1-15$.

35. Wardle J, Chida Y, Gibson EL, Whitaker KL, Steptoe A. Stress and adiposity: a meta-analysis of longitudinal studies. Obesity. 2011;19:771-8.

36. Ball K, DAJM Schoenaker, Mishra GD. Does Psychosocial Stress Explain Socioeconomic Inequities in 9-Year Weight Gain Among Young Women? Obesity. 2017;25:1109-14.

37. Milaneschi Y, Simmons WK, van Rossum EFC, Penninx BWJH. Depression and obesity: evidence of shared biological mechanisms. Mol Psychiatr. 2019;24:18-33.
38. O'Keefe EL, O'Keefe JH, Lavie CJ. Exercise counteracts the cardiotoxicity of psychosocial stress. Mayo Clin Proc. 2019;94:1852-64.

39. Colditz GA, Philpott SE, Hankinson SE. The Impact of the Nurses' Health Study on Population Health: Prevention, Translation, and Control. Am J Public Health. 2016;106:1540-45.

40. Sun Q, Townsend MK, Okereke OI, Franco OH, Hu FB, Grodstein F. Physical Activity at Midlife in Relation to Successful Survival in Women at Age 70 Years or Older. Arch Intern Med. 2010;170:194-201.

41. Nieman DC. Coronavirus disease-2019: a tocsin to our aging, unfit, corpulent, and immunodeficient society. J Sport Health Sci. 2020;9:293-301.

42. Ng SW, Popkin BM. Time use and physical activity: a shift away from movement across the globe. Obes Rev. 2012;13:659-80.

43. Church TS, Thomas DM, Tudor-Locke C, Katzmarzyk PT, Earnest CP, Rodarte RQ, et al. Trends over 5 decades in US occupation-related physical activity and their associations with obesity. Plos ONE. 2011;6:e19657.

44. Piaggi P. Metabolic determinants of weight gain in humans. Obesity. 2019;27:691-9.

45. Holowko N, Jones M, Tooth L, Koupil I, Mishra G. Educational mobility and weight gain over 13 years in a longitudinal study of young women. BMC Public Health. 2014;14:1219.

46. Bowring AL, Peeters A, Freak-Poli R, Lim MSC, Gouillou M, Hellard M. Measuring the accuracy of self-reported height and weight in a community-based sample of young people. BMC Med Res Methodol. 2012;12:1-8. 